\title{
SUSTAINABLE INFRASTRUCTURE: DEVELOPING A RE-USABLE Production Toolkit for EfFicient Online Course Design
}

\author{
Allison Van Beek ${ }^{l}$ and Nadine Ibrahim ${ }^{2}$ \\ ${ }^{1}$ University of Toronto, ${ }^{2}$ University of Waterloo \\ Corresponding Author allison.vanbeek@utoronto.ca
}

\begin{abstract}
Distance education has come a long since the days of mailed correspondence, with little interaction and a timely delay. As technology continues to more robustly offer opportunities for instructors and learners to be distributed but still interactive, more options for course structures emerge. Open online course development for distance education is a time consuming process that requires deep thought about personal pedagogical beliefs and an exploration of the technological tools available (for both development and for use in the course). This paper details the development of an online open course that features not only open access to course content and files, but also to the supporting resources that were used by the team involved in developing the course. These resources build what the authors are calling a "production toolkit," which can be put into action by any individual or team embarking on the development of their own course.

This paper details the background of the project, an overview of the pedagogy that underpins the project, the tools used to produce the course, and the design decisions used during production. Though specific examples are used from the course, the design principles and resources presented can be used across projects.
\end{abstract}

Keywords: Open Distance Course Design, Online Course, Distance Learning, Educational Media Production, Production Toolkit

\section{INTRODUCTION}

The shape of distance courses has shifted since its humble beginnings, primarily due to the increase in technological capacity. There are many educational trends to consider when producing an open distance online course, as well as when re-designing in-class courses for online consumption.

This paper is presented as a guide to open distance course production and includes templates and other resources that form a toolkit to support the transition from face-to-face in person instruction to online and distant. A comparison of what is lost and gained in the process of this conversion to online learning will be presented with an emphasis on teaching strategies and technological skills that instructors need to develop to produce effective online courses. Examples will be used to illustrate lessons learned during the process, with the goals being improved efficiency of course re-design and to share the experiences, both technical and pedagogical, of this specific course redesign process.

The online course production presented in this paper is based on a specific experience, but the guidelines for development are presented in a generalized form to benefit others that wish to convert their courses to open online environments. This method presents a team approach, including an instructor (who acted as the subject matter expert) as well as an education media development team. Aspects that are considered when going from in-class to online include changes in the presentation of the content, flow of content delivery, ways to place emphasis on concepts, built-in checks to gauge student understanding, learning assessments, among others.

\section{BACKGROUND}

The authors draw their experience from an upper-year undergraduate/graduate course on "Infrastructure for Sustainable Cities" taught in-person as a technical elective to Civil Engineering students at the University of Toronto. This course was used as the basis for producing a beginnerlevel online open distance course entitled "Sustainable Cities: Adding an African Perspective." It is free to use for global learners. Online courseware development has been a topic of intense focus within the Engineering Education for Sustainable Cities in Africa (EESC-A) project, as it is a mechanism through which significant impacts in advancing engineering education in Africa is envisioned as possible, through the support of both existing and emerging universities and institutions.

\subsection{Open Distance Education}

While the components in a distance course has shifted since its humble beginnings of correspondence courses, largely due to the increase in technological tools and supports, the spirit of distance education remains the same - to maximize access to education by minimizing costs and 
maximizing flexibility and access (Aydemir, Özkeskin, \& Akkurt, 2014).

For this project, a set of 4 modules was developed (each requiring 2-3 hours of learner time for completion). The modules provide an introduction to concepts of sustainability, urbanization, climate change; strategies for best practices in the design of new cities and redesign of existing ones; and tools and methodologies for environmental assessments, material flows, and urban metabolism.

The modules can be accessed online:

1) Module 1 - Introduction to Urbanization: Growth of World Cities

2) Module 2 - Concepts of Sustainable Cities and Communities

3) Module 3 - Principles of Sustainable Urban Design

4) Module 4 - City Performance Indicators and Methods of Assessment

In addition to the modules themselves, information about the project, Sustainable Cities: Adding an African Perspective, as a whole, is detailed on the project description page, also part of the ETO's website. This website features all the open course, and other, resources that have been developed by the ETO. The primary focus of this digital object repository is to describe to instructors the nature of the re-usable course objects. Instructors can then download the modules and import them into their local learning management systems.

\subsection{Social Constructivist Pedagogy}

This course was designed to support and foster the shared construction of knowledge through interactions between learners as well as the transmission of knowledge. Twoway communication is ubiquitous today thanks to technology and contributes to opportunities to create both synchronous and asynchronous interactions between instructors and learners. Getting this mix of potential interactions correct is still a challenge and it is still difficult to facilitate the construction (and integration) of knowledge for each learner at a remove (Anderson \& Gron, 2011).

Each module includes a discussion point at the end, offering an online option to share thoughts and ideas from their own cities of choice. There is also a reflection element, wherein the learners define their own definition of a sustainable city based on the exploration of the cities throughout the modules.

This paper details the development process and does not provide a complete overview of the supporting learning activities in the course, many of which would also correspond to this pedagogy. In a pilot test of this content, the authors hosted a synchronous webinar using Blackboard Collaborate. This application allowed for learners to participate in the session by asking questions, chatting, and sharing their own content. There were technical challenges but overall the test was a success.
While designed for online, distributed use, there is no reason that the authors can see that these modules could not also be used as supporting content in a flipped or hybrid course wherein the class time is composed of active learning activities.

\subsection{Use of Technology}

Anderson (2009) uses a metaphor to describe the interaction between pedagogy and technology, saying that "the technology sets the beat and creates the music, while the pedagogy defines the moves." Selecting the technology used to support an open distance course is difficult. Often, you are limited by the tools available (or that are institutionally licensed) and those that match the expertise of the team that you are collaborating with. This has to be balanced by the nature of the technology itself and the pedagogy that it embodies. We did our best to use technologies that were open (in nature; not in cost), flexible, and allowed for the designers to build the activities that supported their outcomes, versus having the nature of their activities define by the tools (Bannon, 1981).

A major consideration during development was how the course would be accessed, post-production. We tried to be aware of how and where the materials will be used to help ensure accessibility and access to the course for learners. For example, each of the videos is embedded into the module (versus hosted on a platform like YouTube) to allow for download versus relying on a streaming service and Internet connection.

Table 1: Technology Tools Used for Development

\begin{tabular}{|l|l|}
\multicolumn{1}{|c|}{ Category of Tool } & \multicolumn{1}{c|}{ Software } \\
\hline Screencapture & Techsmith Camtasia \\
\hline Presentation & Microsoft Powerpoint \\
\hline Image Editing & Adobe Illustrator \\
\hline Animation & Adobe After Effects \\
\hline Editing/Audio & Adobe Premiere Pro \\
\hline Rendering & Adobe Media Encoder \\
\hline Module Authoring & Articulate Rise 360 \\
\hline Document Management & G Suite Google Docs \\
\hline Content Management & Dropbox \\
\hline $\begin{array}{l}\text { Accessibility Contrast } \\
\text { Checker }\end{array}$ & $\begin{array}{l}\text { Colour Contrast } \\
\text { Analyzer (CCA) }\end{array}$ \\
\hline
\end{tabular}

\section{PRODUCTION PROCESS}

The workflow for this project was divided into three stages: pre-production, production, and post-production.

Pre-Production: The subject matter expert (SME) met multiple times with the Education Technology Office (ETO) to discuss course details and objectives. The team agreed on a format to share details in the form of a Module Outline document. This document is customizable and 
reflects the production decisions made for your particular project. This document, along with the shared tracking spreadsheet, are key visualizations of the progress of the project and are shared by all team members. This transparency of process was key to the success and continued use of these documents.

Production: For this project, the SME used Powerpoint to create a presentation. This is baseline format is effectively the "lecture" content of the project. The SME self-captured their screen and audio, using Camtasia. While the SME was authoring content, the educational media developer (EMD) could concurrently develop the design brief. In the beginning, review cycles were short and quick, with the ETO providing constructive feedback before too much capturing had occurred. Once the template was agreed upon, and the process finalized, no further edits or modifications to the workflow were made. This helped to avoid scope creep.

Post-Production: The ETO could retrieve the content from the shared cloud service. The EMD could then use this recording, modify it, and apply the design template to the content via Adobe Affect Effects and other editing tools. This removed the pressure from the SME to perfect their content. If enhancing visuals were required, the EMD used Adobe Illustrator. The content was then edited in Premiere Pro, adding any design elements required (ex. opening animation, lower third graphic, etc.). Throughout this stage, the shared spreadsheet was essential. It displayed progress and completion status, feedback, editing notes, and more details.

As the content is published, it is reviewed and finalized, and built into Articulate Rise 360 as a component of a module. While any member of the team can do this, it is recommended that the SME (or someone who will remain with the project) learn this process. This allows some independence from the ETO when edits are required.

\subsection{Workflow Challenges}

There were two major challenges during development. First, time restrictions - as the deadline approached, there was less time to spend creating and animating content, therefore some visual consistency was lost. Second, content sharing - sharing high quality, manipulable graphics was difficult due to the expense of editing tools but low quality illegible content could not be published.

\subsection{Toolkit Resources}

To support the processes involved in the workflow, several documents were developed and are available for download. These resources are available on the ETO's website.

\section{DESIGN PRINCIPLES}

Design has a significant influence on how users observe and process information, evaluate credibility and authority, and informs how valuable they find the experience (Reyna,
2013). Creating thoughtful materials for your online course requires deliberate planning and consistent incorporation of key design principles. Since the goal was to create open and re-usable content, accessible and universal design were core to the design decisions made. These decisions were also balanced against project constraints, namely time for production and project budget.

\subsection{Colour Scheme}

The modules feature simple colour schemes to better showcase information to the learners. Using patterns or graphic backgrounds will likely decrease legibility, and will have an impact on readability. Using light colours, such as white, as a background is recommended (Reyna, 2013). White space visually separates elements, while assisting the learner to understand how all the elements work together, as seen in Figure 1. The colours, blue and green, were selected because they are associated with sustainability and the environment.

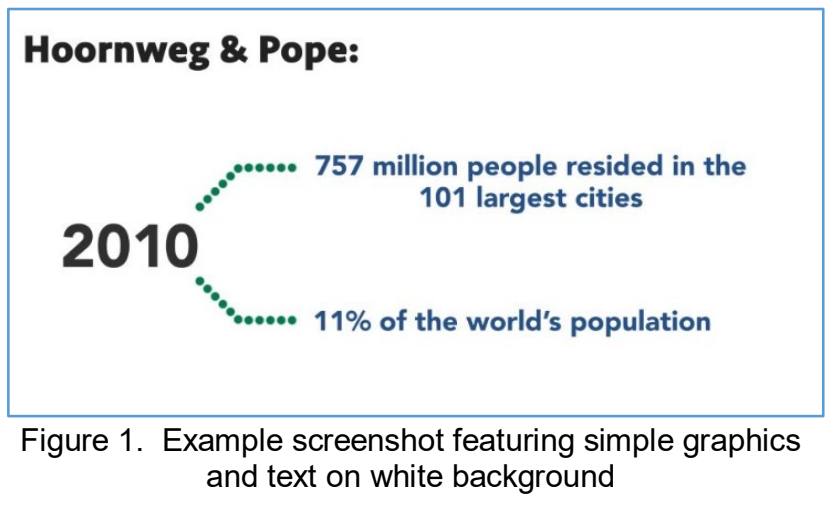

\subsection{Contrast}

Ensuring that similar design elements are noticeably different - that they are contrasting - helps to ensure legibility and clarity for learners. It is also an important accessibility consideration. There was a focus on screen text and background colour to ensure that contrast ratios met WCAG 2.0 Guidelines. To ensure standards were met, a contrast checker was used, the interface of which is seen in Figure 2.

\subsection{Typography}

Text contrast and hierarchy makes clear the primary and secondary elements in a design, even to a learner that is skimming content. Focusing on headline size, weight and style with body copy size, weight and style, enhances readability and usability and can help a reader determine the information hierarchy (what is the most important part on a page. It enables them to quickly navigate the layout, so they can scan for the content they are searching for. Font size generally starts out largest on top, with the most important information, and decreases in size as you move 
down the page, as seen in Figure 3. In North America, reading occurs from left to right and top to bottom, so a top-to-bottom hierarchy is the most natural for readers to navigate. However, this should be re-considered depending on your audience.

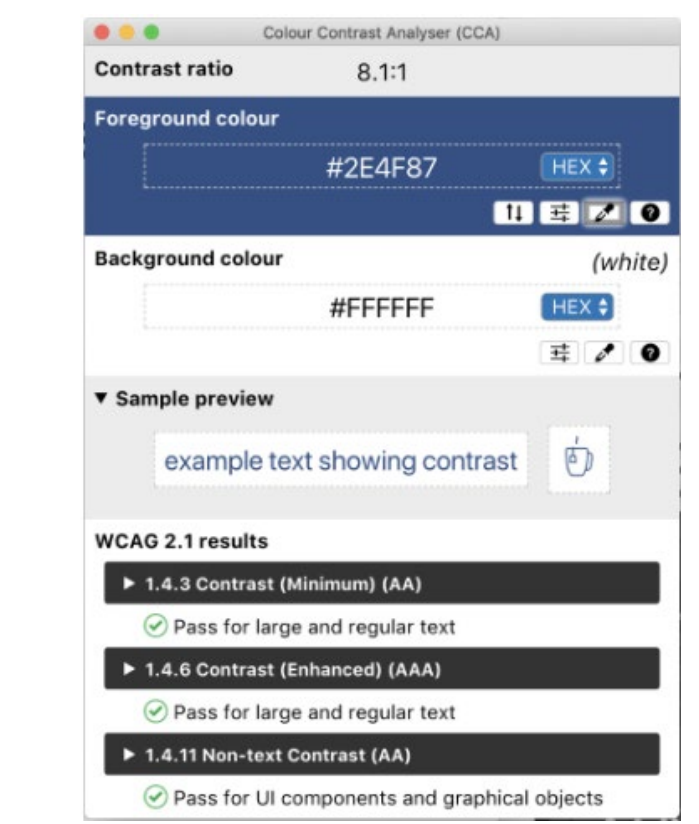

Figure 2. Colour Contrast Analyzer ( $\overline{\mathrm{CCA}})$ Interface featuring pass/fail results

\section{Precept 8 \\ That building and design help in healing the planet.}

\footnotetext{
"It now has become possible to reverse the path of ongoing destruction of the natural world."
}

Figure 3. Example screenshot of text contrast featuring text hierarchy

\subsection{Layout Consistency}

Repetition of elements (both graphic and text) as well as components added consistency and continuity to the course. Consistency across the entire project makes navigation easier. A side benefit is that it also makes production easier. Missing elements are more easily identified, and it is possible to delegate types of tasks across modules.

Each module is composed of the same elements, including a welcome message, learning outcomes, context, and interactive elements and each video uses the same styles, which were defined and detailed in the design brief. The value of the design brief was that it provided a reference point for design decisions and removed the pressure to remember these decisions across time and multiple concurrent projects. It was also easier for the SME to visualize what the final content would look like (see Figure 4, for an example of a "Before" and Figure 5, for an example of an "After") and enabled multiple designers to work on the project at one time.

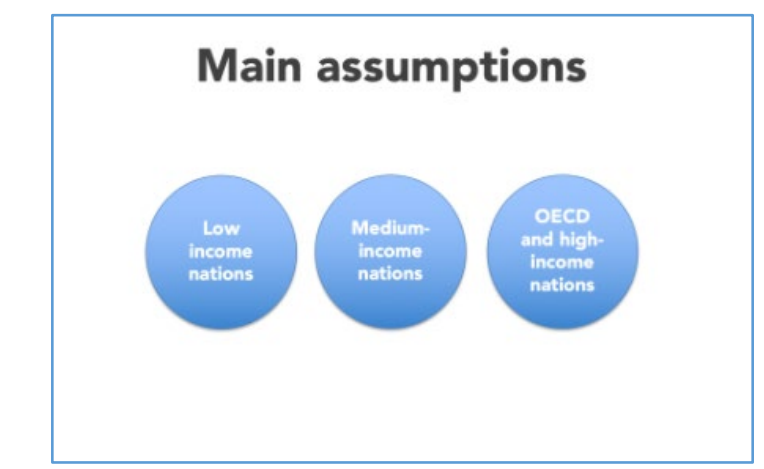

Figure 4. Example screenshot of SME-authored content (Before)

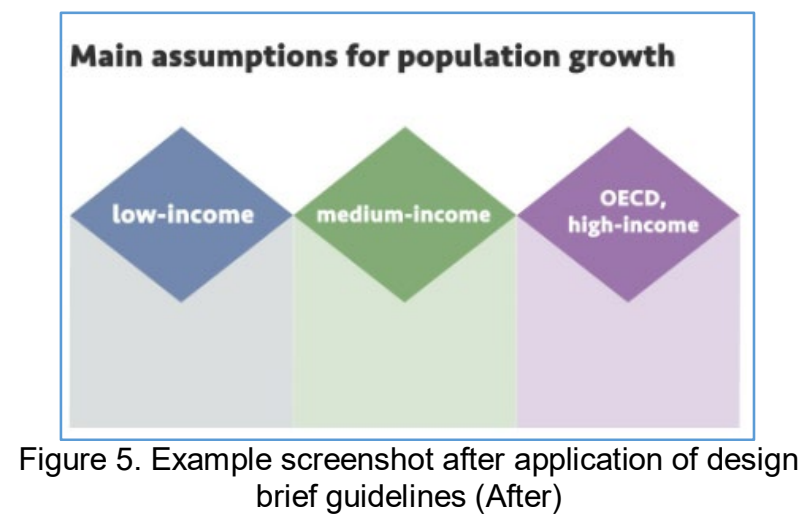

\subsection{Presenting information effectively}

While video production was a large component of this project, the other main element was the web-based module building tool, Articulate Rise 360. Rise is designed for the creation of responsive courses, which play well on different types of devices. While it is easy to use to author modules, there is limited customization and flexibility. There is also no option for translation. If this is a requirement for your project, this lack of functionality would add significantly to your development time. Its strengths are in the ease of building, consistency of format, and collaboration and sharing options, as seen in Figure 6. Rise's pre-built library of standard interactions (including timelines, processes, quizzes, labeled graphics, etc.) make it quick to create interactive content that is also visually attractive. 


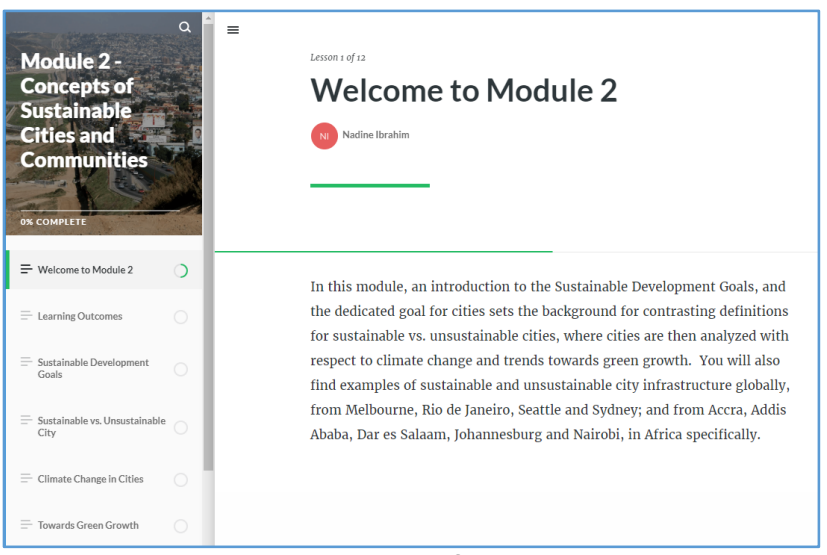

Figure 6. Example screenshot of Rise Module Homepage

\section{PROJECT BUDGET}

This budget details the time spent by the Education Technology Office but does not include the effort and time dedicated by the Instructor.

Table 2: Development Budget by Major Tasks

\begin{tabular}{|l|c|c|}
\hline \multicolumn{1}{|c|}{ Task } & Hours & Cost \\
\hline Graphic Design & 76 & $\$ 3,050.42$ \\
\hline Content Development & 53 & $\$ 2,137.43$ \\
\hline Project Management & 25 & $\$ 838.83$ \\
\hline Technical Support & 12 & $\$ 736.62$ \\
\hline Total & 166 & $\$ 6,763.30$ \\
\hline
\end{tabular}

\section{CONCLUSION}

By outlining the production workflow and providing an overview of major design considerations, it is hoped that sharing this experience in developing an open online distance course will assist others who are embarking on a similar project. While open content is becoming more common, the authors found it difficult to find shared development resources and transparent budgets and timelines. This is likely do to the added effort required to fully document and share this element of the project, more than any loyalty to trade secrets.

To further promote universal design and open access, additions to the project include an e-textbook as well as the recording of case studies featuring experts from the cities featured in the modules.

\section{Acknowledgements}

The authors would like to thank Joanna Lau, who led the design and building of the modules, for her contributions to this project and paper. The course production was funded as part of the Engineering Education for Sustainable Cities in Africa, which was funded by the Dean's Strategic Fund, Connaught Global Challenges Award, and Learning and Education Advancement Fund (LEAF). The resources mentioned in this paper are all licensed under a Creative Commons AttributionNonCommercial-ShareAlike 4.0 International License.

For downloadable resources and further information, visit the Education Technology Office's website (Faculty of Applied Science and Engineering, University of Toronto).

\section{References}

Terry Anderson, "The dance of technology and pedagogy in self-paced distance education," Paper presented at the 23 ICDE World Congress, 2009. Available as of May 05, 2019 from https://auspace.athabascau.ca/handle/2149/2210

Terry Anderson \& Jon Dron, "Three generations of distance education pedagogy," International Review of Research in Open and Distance Learning, 12(3), 80-97, 2011.

Liam Bannon, "From human factors to human actors: The role of psychology and human-computer interaction studies in system design" In J. Greenbaum, \& K. Morten (Eds.), Design at Work: Cooperative Design of Computer Systems. Hillsdale, New Jersey: Lawrence Erlbaum Associates, Inc., pp. 25-45, 1981.

Jorge Reyna, "The importance of visual design and aesthetics in e-learning," Training \& Development Magazine, 40, 2013.

Rick Richardson, Tara Drexler, \& Donna Departe, "Color and contrast in E-learning design: A review of the literature and Recommendations for instructional designers and web developers," Journal of Online Learning and Teaching, 10(4), 657-670, 2013.

Alan Tait, "Education for development: From distance to open education," Journal of Learning for Development, 5(2), 101-115, 2018

Unknown Author, "Understanding WCAG 2.0. "Contrast (Minimum)," Understanding SC 1.4.3. Available as of May 06, 2019 from: https://www.w3.org/TR/UNDERSTANDINGWCAG20/visual-audio-contrast-contrast.html 